\title{
Optimal multi-period consumption and investment with short-sale constraints
}

\author{
Yakup Eser Arısoy ${ }^{\mathrm{a}, *}$, Aslıhan Altay-Salih ${ }^{\mathrm{b}, 1}$, Mustafa Ç Pınar ${ }^{\mathrm{b}, 2}$ \\ ${ }^{a}$ Université Paris Dauphine, DRM Finance, 75775 Paris Cedex 16, France \\ ${ }^{\mathrm{b}}$ Bilkent University, 06533 Ankara, Turkey
}

\section{A R T I C L E I N F O}

\section{Article history:}

Received 15 January 2013

Accepted 16 May 2013

Available online 29 May 2013

\section{JEL classification: \\ G11 \\ G12 \\ D50 \\ D52}

Keywords:

Options

Optimization

Short-sales

Consumption-based CAPM

\begin{abstract}
A B S T R A C T
This article examines agents' consumption-investment problem in a multi-period pure exchange economy where agents are constrained with the short-sale of state-dependent risky contingent claims. In equilibrum, agents hold options written on aggregate consumption in their optimal portfolios. Furthermore, under the specific case of quadratic utility, the optimal risk-sharing rule derived for the pricing agent leads to a multifactor conditional consumption-based capital asset pricing model (CCAPM), where excess option returns appear as factors.
\end{abstract}

(c) 2013 Elsevier Inc. All rights reserved.

\section{Introduction}

Classical asset pricing theories assume no restrictions on short-sales. However, as discussed in Jones and Lamont (2002), regulations and procedures administered by various exchanges, underwriters, and individual brokerage firms can mechanically impede short selling. A recent example is the short-sale ban by four Eurozone countries on banking stocks during the height of Eurozone debt crisis in August 2011. By incorporating this economically plausible constraint into individuals' optimal

\footnotetext{
* Corresponding author. Tel.: +33 (0)14054360.

E-mail addresses: eser.arisoy@dauphine.fr (Y.E. Arısoy), asalih@bilkent.edu.tr (A. Altay-Salih), mustafap@bilkent.edu.tr (M.Ç Pinar).

1 Tel.: $+90(0) 3122902047$.

2 Tel.: $+90(0) 3122901514$.
} 
consumption-investment problem, we first derive agents' optimal portfolios in a general equilibrium framework, and then test its implications for pricing.

The economic intuition behind borrowing, nonnegative wealth and short-sale constraints goes back to the notion of bounded credit by Dybvig and Huang (1988). Cox and Huang (1989) and Merton (1990) consider a similar problem, and solve the individual agent's optimal investment-consumption problem under nonnegativity constraints within a partial equilibrium framework. Vanden (2004) further solves the problem in a single period general equilibrum framework. We examine optimal sharing rules in general equilibrium using a multi-period securities market framework where agents have the possibility to trade time-event contingent claims. Setting the problem in a multi-period framework is more appealing, because the real-life practice is to trade securities through dynamically managed portfolios.

More specifically, we assume a multi-period pure exchange economy with a single consumption good where heterogeneous agents trade time-event contingent claims at each period. In this economy, agents are constrained with the maximum amount that they can borrow and short sell state-contingent claims. In other words, agents can borrow, buy, sell and short-sell time-event contingent claims at time $t$, given that they are able to pay-off their debts and do not reach negative wealth levels at time $t+1$. Restricting short-sales helps agents avoid states of insolvency, and allow them come back to the economy next period with the ability to repay their debts.

The solution to this discrete-time optimization problem implies that agents optimally hold options in their portfolios at each period and state in time. More specifically, in equilibrium, the pricing agent's optimal consumption incorporates the aggregate consumption, and a bundle of short-lived options written on the aggregate consumption with different strike prices. Via their leverage property and nonlinear payoffs, options help agents replicate their optimal consumption patterns, which is otherwise not possible through trading time-event contingent claims under short-sale constraints. Thus, an efficient allocation of resources is achieved at each point in time by holding and dynamically trading short-lived options.

The finding that agents optimally hold options in their equilibrium portfolios in the presence of short-sale constraints is in line with recent stream of studies which argue that the introduction of traded options represents an economically important relaxation of short-sale constraints. ${ }^{3}$ According to these studies, options help bypass short sale constraints on financial markets by enabling investors with negative information about the underlying asset to take synthetic short positions in the option market. ${ }^{4}$ Similarly, in our setting, options help agents bypass short-sale constraints and avoid reaching negative wealth levels, which is not possible through trading of state-contingent claims. Furthermore, our findings lend support to the theory that options are non-redundant securities, and have an allocational role in the economy when markets are incomplete due to market frictions. ${ }^{5}$

Our paper is also closely related to the literature on heterogeneous preferences. In our model, for the case of quadratic utility, differences in endowments will imply that investors with different budget constraints will have different relative risk aversions. Due to differences in initial endowments, when the level of aggregate consumption goes down, there will be agents who will not consume because of their binding constraints. This has an impact on risk sharing rules of remaining agents because they can not share risks with those who do not consume anymore. As aggregate risk gets concentrated on fewer people, this implies higher risk and different optimal wealth processes for agents whose constraints do not bind. This is why some investors might hold options in their optimal portfolios in order to hedge that increased risk. Indeed, Dumas (1989) shows that the distribution of wealth plays the role

\footnotetext{
${ }^{3}$ See theoretical contributions of Chen et al. (2002), Duffie et al. (2002), Hong and Stein (2003), and Scheinkman and Xiong (2003), and empirical studies by Diether et al. (2002), Geczy et al. (2002), Chen and Singal (2003).

${ }^{4}$ Although similar in spirit, this paper differs from the above studies by focusing on short-sale of state-contingent ArrowDebreu securities rather than short-sale of long-lived complex securities. However, since complex securities can be created using bundles of state-contingent claims, the short-sale constraint of the type studied in this paper can be viewed as an indirect constraint on short-sale of more complex securities such as common stocks or bonds.

${ }^{5}$ See Grossman (1988), Back (1993), Grossman and Zhou (1996), Basak and Croitoru (2000), Liu and Pan (2003), Vanden (2004), and Buraschi and Jiltsov (2006) for articles that motivate options trading under different market imperfections.
} 
of an additional state variable that investors want to hedge and different levels of risk aversion imply investors' demand for portfolio insurance. ${ }^{6}$

Finally, the outlined model has implications for asset pricing. Under the assumption of quadratic utility, the optimal sharing rule for the pricing agent yields a multifactor conditional consumptionbased capital asset pricing model (CCAPM), where the first factor is the change in log aggregate consumption, and other factors being excess returns on options written on the aggregate consumption. In an asset pricing context, this implies that option betas should help explain the cross section of securities returns. Furthermore, if options account for systematic risks that are not captured by consumption beta, then their returns should also be priced risk factors, and play a role in constructing the stochastic discount factor of the economy. In different contexts, Vanden (2004) and Husmann and Todorova (2011) develop CAPM based asset pricing and option pricing models, respectively. To the best of authors' knowledge, this is the first study that documents the significance of excess option returns within a CCAPM framework, thus the model developed here has implications for asset pricing, and capital markets theories.

The rest of the article is organized as follows. Section 2 introduces the problem, and solves the optimal risk-sharing rules for agents in the economy. Section 3 subsequently derives the corresponding asset pricing model. Finally, Section 4 offers concluding remarks.

\section{The model}

There are $I$ agents in the economy indexed by $i=1, \ldots, I$. Agents live in a multi-period pure exchange economy $(t=0,1, \ldots, T)$ with reconvening markets and agree on the possibilities of occurrences of events in the economy. Each event, $a_{t}$, is a collection of states, $\omega . \Omega$ denotes the collection of all possible states of nature, and the true state of the nature is partially revealed to individuals over time.

A single consumption good is available for consumption at each trading date. Individuals are endowed with time-0 consumption and time-event contingent claims, $e_{i}(0), e_{i}\left(a_{t}\right), a_{t} \in \mathcal{F}_{t}$; $t=0,1, \ldots, T$, and they have the possibility to trade these claims after $t=0 .{ }^{7}$

We further assume that (i) all agents have the same information structure, $\mathcal{F}_{t}$; (ii) all agents agree on the possible states of the economy; (iii) all agents are endowed with an initial wealth; (iv) all agents have time-additive and state-independent von Neumann-Morgenstern utility functions with linear risk tolerance, and identical cautiousness; and (v) all agents face short-sale constraints, i.e. they are not allowed to reach states of negative holdings of time-event contingent-claims at all states and at all periods. Under these assumptions, the model proceeds as follows.

Individual $i$ has preferences for time- 0 consumption and time-event contingent claims that are increasing, strictly concave, and differentiable, i.e. $u_{i 0}\left(z_{i 0}\right)+\sum_{T}^{t=1} \sum_{a_{t} \in \mathcal{F}_{t}} p_{a_{t}} u_{i, t}\left(z_{i}\left(a_{t}\right)\right) \cdot p_{a_{t}}$ is the homogeneously agreed probability of the occurrence of event $a_{t} \in \mathcal{F}_{t}, z(0)$ is the time- 0 consumption good, and $z\left(a_{t}\right)$ are the payoffs of the time-event contingent claims in the event $a_{t} \in \mathcal{F}_{t}$ for $t \geqslant 1$, respectively. Agents share exogenously fixed aggregate consumption $C\left(a_{t}\right)$ from $t=1, \ldots, T$ and maximize their expected utilities over their lifetime, while facing budget and short-sale constraints. We examine the optimal allocation of aggregate consumption among agents subject to budget and short-sale constraints in this multi-period securities market economy.

Following Huang and Litzenberger (1988), we define $\phi(0)$ as the price of the time-0 consumption good and $\phi_{a_{s}}\left(a_{t}\right)$ as the ex-dividend price for the time-event contingent claim, paying off at time $s$ in event $a_{s}$, conditional on the occurrence of event $a_{t}$ at time t, where

$$
\phi_{a_{s}}\left(a_{t}\right)= \begin{cases}\frac{\phi_{a_{s}}}{\phi_{a_{t}}} & \text { if } t<s \text { and } a_{s} \subset a_{t} \\ 1 & \text { otherwise }\end{cases}
$$

\footnotetext{
${ }^{6}$ See also Wang (1996), Chan and Kogan (2002), Bhamra and Uppal (2009), Gârlenau and Panageas (2012), and Longstaff and Wang (2012) for related studies on preference heterogeneity.

7 A time-event contingent claim is a security that pays one unit of consumption at a trading date $t \geqslant 1$ in an event $a_{t} \in \mathcal{F}_{t}$, and nothing otherwise.
} 
Also, for $t<s$, define $p_{a_{s}}\left(a_{t}\right)$ to be the conditional probability of event $a_{s}$ given that at time $t$ event $a_{t}$ occurs, so that

$$
p_{a_{s}}\left(a_{t}\right)= \begin{cases}\frac{p_{a_{s}}}{p_{a_{t}}} & \text { if } a_{s} \subseteq a_{t} \\ 0 & \text { if } a_{s} \not \subset a_{t}\end{cases}
$$

With the above assumptions, the problem (P) can be formulated as follows:

$$
\begin{array}{cc}
\operatorname{Max}_{z_{i}(0), z_{i}\left(a_{t}\right)} & u_{i 0}\left(z_{i 0}\right)+\sum_{t=1}^{T} \sum_{a_{s} \in \mathcal{F}_{s}} p_{a_{s}}\left(a_{t}\right) u_{i, t}\left(z_{i}\left(a_{s}\right)\right) \\
& a_{s} \subseteq a_{t} \\
\text { subject to } & \phi_{0}\left(z_{i 0}\right)+\sum_{\substack{t=1 \\
a_{s} \in \mathcal{F}_{s}}} \phi_{a_{s}}\left(a_{t}\right) z_{i}\left(a_{s}\right)=\phi_{0}\left(e_{i 0}\right)+\sum_{t=1}^{T} \sum_{\substack{a_{s} \in \mathcal{F}_{s} \\
a_{s} \subseteq a_{t}}} \phi_{a_{s}}\left(a_{t}\right) e_{i}\left(a_{s}\right) \\
& z_{i}(0) \geqslant 0, a_{t} \\
z_{i}\left(a_{s}\right) \geqslant 0 \quad \forall a_{s}, a_{s} \subseteq a_{t} .
\end{array}
$$

The first and second constraints represent the budget, and short-sale constraints, respectively. The solution to the above problem requires the solution of the Lagrangian and its associated Kuhn-Tucker $(\mathrm{K}-\mathrm{T})$ conditions. The Kuhn-Tucker conditions for the Lagrangian of $\mathrm{P}\left(a_{t}\right)$ evaluated at $c_{i}\left(a_{t}\right)$ and $c_{i}\left(a_{s}\right)$ are given by,

$$
\begin{aligned}
& u_{i, t}^{\prime}\left(c_{i}\left(a_{t}\right)\right)-\gamma_{i, a_{t}}=0 \\
& p_{a_{s}}\left(a_{t}\right) u_{i, s}^{\prime}\left(c_{i}\left(a_{s}\right)\right)-\gamma_{i, a_{t}} \phi_{a_{s}}\left(a_{t}\right)=0 \\
& \mu_{i, 0}\left(c_{i}\left(a_{t}\right)\right)=0 \\
& \mu_{i, a_{s}}\left(c_{i}\left(a_{s}\right)\right)=0
\end{aligned}
$$

Because agents unanimously agree on the price process of time-event contingent claims, $\phi_{a_{s}}\left(a_{t}\right)$, and the conditional probability of events, $p_{a_{s}}\left(a_{t}\right)$, Eq. (2) implies that for any two agents $i$ and $j$ whose short-sale constraints do not bind, their marginal rates of substitutions must be equal in an efficient allocation, i.e.

$$
\frac{u_{i, s}^{\prime}\left(c_{i}\left(a_{s}\right)\right)}{\gamma_{i, a_{t}}}=\frac{u_{j, s}^{\prime}\left(c_{j}\left(a_{s}\right)\right)}{\gamma_{j, a_{t}}}
$$

Furthermore, from Eqs. (1) and (3), if the ith agent's short-sale constraint binds, then $c_{i}\left(a_{t}\right)=0$, and if it does not bind, then $c_{i}\left(a_{t}\right)=u_{i, t}^{\prime-1}\left(\gamma_{i, a_{t}}\right)$. Letting $\gamma_{i, a_{t}}=\gamma_{i, t} \frac{\phi_{a_{t}}}{p_{a_{t}}}$, and using the definitions of $\phi_{a_{s}}\left(a_{t}\right)$ and $p_{a_{s}}\left(a_{t}\right)$, the optimal time-t consumption can be written as

$$
c_{i}\left(a_{t}\right)=\max \left[0, u_{i, t}^{\prime-1}\left(\gamma_{i, a_{t}}\right)\right]=\max \left[0, u_{i, t}^{\prime-1}\left(\gamma_{i, t} \frac{\phi_{a_{t}}}{p_{a_{t}}}\right)\right]
$$

To derive the corresponding optimal sharing rules in equilibrium, we follow a methodology similar to Vanden (2004), and write the aggregate consumption in the economy at time $t$, and event $a_{t}$ as

$$
C\left(a_{t}\right)=\sum_{i=1}^{I} c_{i}\left(a_{t}\right)=\sum_{i=1}^{I} \max \left[0, u_{i, t}^{\prime-1}\left(\gamma_{i, t} \frac{\phi_{a_{t}}}{p_{a_{t}}}\right)\right] .
$$

Defining a real-valued function $\Delta(x)$, such that $\Delta(x)=\sum_{i=1}^{l} \max \left[0, u_{i, t}^{\prime-1}\left(\gamma_{i, t} x\right)\right]$ one can write $\Delta\left(\frac{\phi_{a_{t}}}{p_{a_{t}}}\right)=C\left(a_{t}\right)$, and $\frac{\phi_{a_{t}}}{p_{a_{t}}}=\Delta^{-1}\left(C\left(a_{t}\right)\right)$. Therefore, the $i$ th agent's optimal sharing rule becomes

$$
c_{i}\left(a_{t}\right)=\max \left[0, u_{i, t}^{\prime-1}\left(\gamma_{i, t} \Delta^{-1}\left(C\left(a_{t}\right)\right)\right)\right]
$$

In the above expression, $\Delta^{-1}$ is the inverse mapping of the function $\Delta$ on the interval, in which $\Delta$ is strictly increasing. Furthermore, the assumptions that all agents have linear risk tolerance with identical cautiousness and at least one agent has finite marginal utility at zero consumption level imply 
that utility functions can be in the form of negative exponential utility, logarithmic utility, or power utility. In the remainder of the paper, we restrict ourselves to the case of power utility class and more specifically to quadratic utility function, however, note that as long as assumption $i v$ holds, the closedform solution to Eq. (7) for the power utility case can easily be extended to exponential and logarithmic utility classes. The solution to the discrete-time optimization problem in (P) under quadratic utility can be summarized with the following proposition.

Proposition 1. In an economy where agents possess quadratic utilities, i.e., $u_{i, t}\left(c_{i}\left(a_{t}\right)\right)=c_{i}\left(a_{t}\right)-\frac{b}{2} c_{i}\left(a_{t}\right)^{2}$, $i=1,2, \ldots$, I and where agents can be ranked by the relation, $\gamma_{1, t}^{-1}>\gamma_{2, t}^{-1}>\cdots>\gamma_{I, t}^{-1}$, the closed form solution to $\Delta^{-1}\left(C\left(a_{t}\right)\right)$ is given by

$$
\Delta^{-1}\left(C\left(a_{t}\right)\right)=\left\{\begin{array}{cc}
\frac{1-b C\left(a_{t}\right)}{\gamma_{1, t}} & 0<C\left(a_{t}\right) \leqslant K_{1, t} \\
\frac{2-b C\left(a_{t}\right)}{\bar{\gamma}_{2, t}} & K_{1, t}<C\left(a_{t}\right) \leqslant K_{2, t} \\
\vdots & \vdots \\
\frac{I-b C\left(a_{t}\right)}{\tilde{\gamma}_{1, t}} & K_{I-1, t}<C\left(a_{t}\right)
\end{array}\right.
$$

where $\bar{\gamma}_{k, t}=\sum_{i=1}^{I} \gamma_{i, t}$, and the constants, $K_{i, t}, i=1,2, \ldots, I-1$ are given by

$$
K_{1, t}=\Delta\left(\frac{1}{\gamma_{2, t}}\right), K_{2, t}=\Delta\left(\frac{1}{\gamma_{3, t}}\right), \ldots, K_{I-1, t}=\Delta\left(\frac{1}{\gamma_{I, t}}\right) .
$$

Furthermore, the optimal sharing rule for the agent indexed by $i=1$ is given by

$$
c_{1}\left(a_{t}\right)=C\left(a_{t}\right)-\sum_{j=1}^{I-1} \frac{\gamma_{1, t} \gamma_{j+1, t}}{\bar{\gamma}_{j, t} \bar{\gamma}_{j+1, t}} \max \left[0, C\left(a_{t}\right)-K_{j, t}\right]
$$

where

$$
K_{j, t}=\frac{1}{b}\left(j-\frac{\bar{\gamma}_{j, t}}{\gamma_{j+1, t}}\right), \quad j=1,2, \ldots, I-1 .
$$

Proof. See the Supplementary Material the proof.

The solution to $\Delta^{-1}$ is piecewise linear in aggregate consumption in each state. This further implies piecewise linear risk-sharing rules for all agents in the economy, i.e. optimal sharing rules are determined depending on the level of aggregate consumption in each state and whether an agent's shortsale constraint binds or not in that given state. The optimal sharing rules imply that, at each period $t$ and each state $a_{t}$, there is an agent indexed by $i=1$, whose short-sale constraint never binds. We call this agent as the pricing agent of the economy. The optimal risk-sharing rule for the pricing agent in period $\mathrm{t}$ and state $a_{t}$ is given by:

$$
c_{1}\left(a_{t}\right)=C\left(a_{t}\right)-\sum_{j=1}^{I-1} \frac{\gamma_{1, t} \gamma_{j+1, t}}{\bar{\gamma}_{j, t} \bar{\gamma}_{j+1, t}} \max \left[0, C\left(a_{t}\right)-K_{j, t}\right] .
$$

Thus, the pricing agents optimal sharing rule is determined by not only the aggregate consumption, but also positions in call options written on the aggregate consumption with strike prices $K_{j, t}{ }^{8}$

\section{Implications for asset pricing}

The fact that the pricing agent optimally holds options in her portfolio has important pricing consequences.

\footnotetext{
${ }^{8}$ Note that, by using the put-call parity, the optimal solution for the pricing agent and all other agents can be written in terms of put options, or combination of put and call options.
} 
Proposition 2. The optimal portfolio held by the pricing agent indexed with $i=1$, and having a quadratic utility function specified in Proposition 1 results in a multifactor conditional CCAPM, where the first factor is the change in log aggregate consumption, and the remaining I-1 factors are option returns with strike prices given by $K_{j, t}=\frac{1}{b}\left(j-\frac{\bar{\gamma}_{j, t}}{\gamma_{j+1, t}}\right), j=1,2, \ldots, I-1$. The multifactor conditional CCAPM is represented by

$$
E\left[\widetilde{\mathbf{R}}(\mathbf{t}) \mid \mathcal{F}_{t-1}\right]-R_{f}(t) \mathbf{1}=\beta_{N c_{1}} \beta_{c_{1} c_{1}}^{-1}\left[E\left[\widetilde{R}_{c_{1}}(t) \mid \mathcal{F}_{t-1}\right]-R_{f}(t) \mathbf{1}\right]
$$

where $\beta_{\mathrm{Nc}_{1}}$ is the variance-covariance matrix of $N$ risky assets, and $\beta_{c_{1} c_{1}}^{-1}$ is the variance-covariance matrix of pricing agent's optimal portfolio.

Proof. Let the sequence $\mathcal{F}_{t}, t=0,1, \ldots, T$ be an information structure, such that the possible realizations of $\mathcal{F}_{t}$ from time 0 to time $t$ generate a state space, $\Omega$. Assume that the pricing agent is endowed with this information structure, and has a quadratic utility given by $u_{1, t}\left(c_{1}(t)\right)=c_{1}(t)-\frac{b}{2} c_{1}^{2}(t)$, which is strictly concave and differentiable everywhere. Also, assume that $\mathcal{F}_{0}$ is just $\Omega$.

The price of a long-lived security in this economy is given by

$$
\begin{gathered}
S_{j}\left(a_{t}, t\right)=\sum_{s=t+1}^{T} \sum_{a_{s} \in \mathcal{F}_{s}} \phi_{a_{s}}\left(a_{t}\right) X_{j}\left(a_{s}\right) \\
a_{s} \subseteq a_{t}
\end{gathered}
$$

where $X_{j}\left(a_{s}\right)$ is the dividend paid by security $j$ in event $a_{s} \cdot{ }^{9}$

By using Kuhn-Tucker Eqs. (1) and (2), one can rewrite the price process of a long-lived security as

$$
\begin{aligned}
S_{j}\left(a_{t}, t\right)=\sum_{s=t+1}^{T} \sum_{a_{s} \in \mathcal{F}_{s}} \frac{p_{a_{s}}\left(a_{t}\right) u_{1, s}^{\prime}\left(c_{1}\left(a_{s}\right)\right)}{u_{1, t}^{\prime}\left(c_{1}\left(a_{t}\right)\right)} X_{j}\left(a_{s}\right) \\
a_{s} \subseteq a_{t}
\end{aligned}
$$

By using the definition of $S_{j}\left(a_{t-1}, t-1\right)$ from Eq. (8),

$$
\begin{aligned}
S_{j}\left(a_{t-1}, t-1\right)= & \sum_{\substack{a_{s} \in \mathcal{F}_{s} \\
\\
a_{t} \subseteq a_{t}-1}} \frac{p_{a_{s}}\left(a_{t-1}\right) u_{1, t}^{\prime}\left(c_{1}\left(a_{t}\right)\right)}{u_{1, t-1}^{\prime}\left(c_{1}\left(a_{t-1}\right)\right)}\left(X_{j}\left(a_{t}\right)+S_{j}\left(a_{t}, t\right)\right)
\end{aligned}
$$

Also, by using the definition of the expected value, the random ex-dividend price of a long-lived security is given by

$$
\begin{aligned}
& S_{j}(t-1)=E\left[\sum_{s=t}^{T} \frac{u_{1, s}^{\prime}\left(c_{1}(s)\right)}{u_{1, t-1}^{\prime}\left(c_{1}(t-1)\right)} X_{j}(s) \mid \mathcal{F}_{t-1}\right] \\
& S_{j}(t-1)=E\left[\frac{u_{1, t}^{\prime}\left(c_{1}(t)\right)}{u_{1, t-1}^{\prime}\left(c_{1}(t-1)\right)}\left(X_{j}(t)+S_{j}(t)\right) \mid \mathcal{F}_{t-1}\right]
\end{aligned}
$$

By using the definition of expected return, i.e. $E\left[\widetilde{R}_{j}(t)\right]=\frac{E\left[X_{j}(t)+S_{j}(t)\right]}{S_{j}(t-1)}$, the expected return process for a long-lived security j can be written as,

$$
1=E\left[\frac{u_{1, t}^{\prime}\left(c_{1}(t)\right)}{u_{1, t-1}^{\prime}\left(c_{1}(t-1)\right)}\left(1+\widetilde{R}_{j}(t)\right) \mid \mathcal{F}_{t-1}\right]
$$

From the definition of the covariance, Eq. (13) can be rewritten as

$$
1=\operatorname{Cov}\left[\frac{u_{1, t}^{\prime}\left(c_{1}(t)\right)}{u_{1, t-1}^{\prime}\left(c_{1}(t-1)\right)}, 1+\widetilde{R}_{j}(t) \mid \mathcal{F}_{t-1}\right]+E\left[\frac{u_{1, t}^{\prime}\left(c_{1}(t)\right)}{u_{1, t-1}^{\prime}\left(c_{1}(t-1)\right)} \mid \mathcal{F}_{t-1}\right] E\left[1+\widetilde{R}_{j}(t) \mid \mathcal{F}_{t-1}\right]
$$

\footnotetext{
${ }^{9}$ A long-lived security is a complex security that is available for trading at all periods, and is composed of time- 0 consumption good and a bundle of time-event contingent claims, and is represented by $X=\left\{X_{0}, X_{a_{t}} ; a_{t} \in \mathcal{F}_{t}, t=1, \ldots, T\right\}$, where $X_{0}$ and $X_{a_{t}}$ are the dividends paid at time 0 , and at time $t$ in event $a_{t}$ in units of consumption good, respectively.
} 
Furthermore, the existence of a risk-free asset implies that

$$
\frac{1}{1+R_{f}(t)}=E\left[\frac{u_{1, t}^{\prime}\left(c_{1}(t)\right)}{u_{1, t-1}^{\prime}\left(c_{1}(t-1)\right)} \mid \mathcal{F}_{t-1}\right]
$$

Substituting (15) into (14), we have

$$
\begin{aligned}
& E\left[\widetilde{R}_{j}(t) \mid \mathcal{F}_{t-1}\right]-R_{f}(t)=-\left(1+R_{f}(t)\right) \operatorname{Cov}\left[\widetilde{R}_{j}(t), \frac{u_{1, t}^{\prime}\left(c_{1}(t)\right)}{u_{1, t-1}^{\prime}\left(c_{1}(t-1)\right)} \mid \mathcal{F}_{t-1}\right] \\
& E\left[\widetilde{R}_{j}(t) \mid \mathcal{F}_{t-1}\right]-R_{f}(t)=-\left(1+R_{f}(t)\right) \operatorname{Cv}\left[\widetilde{R}_{j}(t), \widetilde{R}_{c_{1}}(t) \mid \mathcal{F}_{t-1}\right]
\end{aligned}
$$

Because Eq. (16) holds for any traded asset, it should also hold for pricing agent's portfolio, $\widetilde{R}_{c_{1}}(t)=\left(\widetilde{R}_{C}(t), \widetilde{R}_{o_{1}}(t), \ldots, \widetilde{R}_{o_{I-1}}(t)\right)^{T}$, where $\widetilde{R}_{C}(t)$ is the growth in aggregate consumption, and $\widetilde{R}_{o_{j}}(t)$ is the return on option $j$ at time $t$. Thus,

$$
E\left[\widetilde{R}_{c_{1}}(t) \mid \mathcal{F}_{t-1}\right]-R_{f}(t)=-\left(1+R_{f}(t)\right) \operatorname{Cov}\left[\widetilde{R}_{c_{1}}^{T}(t), \widetilde{R}_{c_{1}}(t) \mid \mathcal{F}_{t-1}\right]
$$

Substituting (17) into (16) gives,

$$
E\left[\widetilde{R}_{j}(t) \mid \mathcal{F}_{t-1}\right]-R_{f}(t)=\frac{\operatorname{Cov}\left(\widetilde{R}_{j}(t), \widetilde{R}_{c_{1}}(t) \mid \mathcal{F}_{t-1}\right)}{\operatorname{Cov}\left(\widetilde{R}_{c_{1}}^{T}(t), \widetilde{R}_{c_{1}}(t) \mid \mathcal{F}_{t-1}\right)}\left(E\left[\widetilde{R}_{c_{1}}(t) \mid \mathcal{F}_{t-1}\right]-R_{f}(t)\right)
$$

In general, for a vector of risky assets, $\widetilde{\mathbf{R}}(t)=\left(\widetilde{R}_{1}(t), \widetilde{R}_{2}(t), \ldots, \widetilde{R}_{N}(t)\right)^{T}$, one can write:

$$
E\left[\widetilde{\mathbf{R}}(t) \mid \mathcal{F}_{t-1}\right]-R_{f}(t) \mathbf{1}=\frac{\operatorname{Cov}\left(\widetilde{\mathbf{R}}(t), \widetilde{R}_{c_{1}}(t) \mid \mathcal{F}_{t-1}\right)}{\operatorname{Cov}\left(\widetilde{R}_{c_{1}}^{T}(t), \widetilde{R}_{c_{1}}(t) \mid \mathcal{F}_{t-1}\right)}\left(E\left[\widetilde{R}_{c_{1}}(t) \mid \mathcal{F}_{t-1}\right]-R_{f}(t) \mathbf{1}\right)
$$

where $\operatorname{Cov}\left(\widetilde{\mathbf{R}}(t), \widetilde{R}_{c_{1}}(t) \mid \mathcal{F}_{t-1}\right)$ is an $\mathrm{N} \times$ I conditional variance-covariance matrix of returns on $N$ risky assets with the return on the representative agent's portfolio, $\operatorname{Cov}\left(\widetilde{R}_{c_{1}}^{T}(t), \widetilde{R}_{c_{1}}(t) \mid \mathcal{F}_{t-1}\right)$ is the I $\times$ I conditional variance matrix of the return on the representative agent's portfolio, and $\widetilde{R}_{c_{1}}(t)=\left(\widetilde{R}_{C}(t), \widetilde{R}_{o_{1}}(t), \ldots, \widetilde{R}_{o_{I-1}}(t)\right)^{T}$ is the $\mathrm{I} \times 1$ vector of returns for the representative agent's portfolio. Eq. (19) can be written in a multibeta representation as,

$$
E\left[\widetilde{\mathbf{R}}(t) \mid \mathcal{F}_{t-1}\right]-R_{f}(t) \mathbf{1}=\beta_{N c_{1}} \beta_{c_{1} c_{1}}^{-1}\left[E\left[\widetilde{R}_{c_{1}}(t) \mid \mathcal{F}_{t-1}\right]-R_{f}(t) \mathbf{1}\right]
$$

where

$$
\beta_{N c_{1}}=\left(\begin{array}{cccc}
\operatorname{Cov} v_{t-1}\left(\widetilde{R}_{1}(t), \widetilde{R}_{C}(t)\right) & \operatorname{Cov} v_{t-1}\left(\widetilde{R}_{1}(t), R_{o_{1}}(t)\right) & \cdots & \operatorname{Cov} v_{t-1}\left(\widetilde{R}_{1}(t), \widetilde{R}_{o_{I-1}}(t)\right) \\
\operatorname{Cov} t-1\left(\widetilde{R}_{2}(t), \widetilde{R}_{C}(t)\right) & \operatorname{Cov} v_{t-1}\left(\widetilde{R}_{1}(t), \widetilde{R}_{o_{1}}(t)\right) & \cdots & \operatorname{Cov} v_{t-1}\left(\widetilde{R}_{1}(t), \widetilde{R}_{o_{I-1}}(t)\right) \\
\vdots & \vdots & \ddots & \vdots \\
\operatorname{Cov} v_{t-1}\left(\widetilde{R}_{N}(t), \widetilde{R}_{C}(t)\right) & \operatorname{Cov} v_{t-1}\left(\widetilde{R}_{1}(t), \widetilde{R}_{o_{1}}(t)\right) & \cdots & \operatorname{Cov} t-1\left(\widetilde{R}_{1}(t), \widetilde{R}_{o_{I-1}}(t)\right)
\end{array}\right)
$$

and

$$
\beta_{c_{1} c_{1}}=\left(\begin{array}{cccc}
\operatorname{Var}_{t-1}\left(\widetilde{R}_{C}(t)\right) & \operatorname{Cov}_{t-1}\left(\widetilde{R}_{C}(t), \widetilde{R}_{o_{1}}(t)\right) & \cdots & \operatorname{Cov} \\
\operatorname{Cov} v_{t-1}\left(\widetilde{R}_{o_{1}}(t), \widetilde{R}_{C}(t)\right) & \operatorname{Var}_{t-1}\left(\widetilde{R}_{o_{1}}(t)\right) & \cdots & \widetilde{C o v}_{t-1}\left(\widetilde{R}_{o_{I-1}}(t), \widetilde{R}_{o_{I-1}}(t)\right) \\
\vdots & \vdots & \ddots & \vdots \\
\operatorname{Cov}_{t-1}\left(\widetilde{R}_{o_{I-1}}(t), \widetilde{R}_{C}(t)\right) & \operatorname{Cov}_{t-1}\left(\widetilde{R}_{o_{I-1}}(t), \widetilde{R}_{o_{1}}(t)\right) & \cdots & \operatorname{Var}_{t-1}\left(\widetilde{R}_{o_{I-1}}(t)\right)
\end{array}\right)
$$


This completes the proof.

The result of the classical setting of a multi-period securities market within rational expectations is the well-known capital asset pricing model (CAPM). On the other hand, the presence of short-sale constraints in the multi-period economy studied here results in a multifactor CCAPM where option returns appear as factors. Proposition 2 suggests that when agents in the economy are constrained with the maximum amount allowed for short-sale, the expected return on any risky asset in this economy is linearly related to consumption growth, and excess returns on a bundle of options written on the aggregate consumption. To the best of our knowledge, there have not been any multifactor models of asset pricing that combines the CCAPM framework with options.

\section{Conclusion}

This article solves agents' consumption-investment problem in a multi-period pure exchange economy under short-sale constraints. The solution implies that, when restricted with this economically plausible constraint, agents optimally hold options in their equilibrium portfolios. Furthermore, assuming a quadratic utility, the optimal risk-sharing rule for the pricing agent leads to a multifactor conditional CCAPM, where excess option returns written on the aggregate consumption span the security market hyperplane.

The first result confirms the theory that options are non-redundant securities when frictionless markets assumption breaks down. By holding options in their optimal portfolios, and dynamically trading them at each period, agents might bypass restrictions on short sales and still achieve Pareto efficient allocations. Via their leverage property and nonlinear payoffs, options help agents achieve their optimal consumption-investment patterns, which is otherwise not possible in the existence of short-sale constraints. This finding lends support to theories regarding the allocational role of options in the economy.

The economic intuition behind the first result is also closely related to the literature on preference heterogeneity. For the case of quadratic utilitity, differences in endowments imply different risk aversion for investors with different budget constraints. When aggregate consumption goes down some agents will not consume as a result of their binding constraints. Remaining agents can not share risk with those who do not consume anymore, resulting in increased risk for them in states when aggregate consumption is lower. This is why investors whose constraint do not bind might want to hedge against increased aggregate risk by holding levered claims on aggregate consumption in their optimal portfolios.

Our second result has implications regarding asset pricing theories. The multifactor conditional CCAPM derived in this article implies that option returns should help explain securities returns. In other words, option returns should account for systematic risk factors which are not captured by an asset's sensitivity with respect to changes in aggregate consumption. This is consistent with recent empirical studies that document the significance of option returns in explaining the cross-section of securities returns.

\section{Appendix A. Supplementary data}

Supplementary data associated with this article can be found, in the online version, at http:// dx.doi.org/10.1016/j.frl.2013.05.007.

\section{References}

Back, K., 1993. Asymmetric information and options. Rev. Financial Stud. 6, 435-472.

Basak, S., Croitoru, B., 2000. Equilibrium mispricing in a capital market with portfolio constraints. Rev. Financial Stud. 13, 715748.

Bhamra, H., Uppal, R., 2009. The effect of introducing a non-redundant derivative on the volatility of stock-market returns when agents differ in risk aversion. Rev. Financial Stud. 22, 2303-2330.

Buraschi, A., Jiltsov, A., 2006. Model uncertainty and option markets with heterogeneous beliefs. J. Finance 61, $2841-2897$.

Chan, Y.L., Kogan, L., 2002. Catching up with the Joneses: heterogeneous preferences and the dynamics of asset prices. J. Polit. Econ. 110, 1255-1285. 
Chen, H., Singal, V., 2003. Role of speculative short sales in price formation: the case of the weekend effect. J. Finance 58, 685705.

Chen, J., Hong, H., Stein, J.C., 2002. Breadth of ownership and stock returns. J. Financial Econ. 66, 171-205.

Cox, J., Huang, C., 1989. Optimum consumption and portfolio choices when asset prices follow a diffusion process. J. Econ. Theory 49, 33-83.

Diether, K.B., Malloy, C.J., Scherbina, A., 2002. Differences of opinion and the cross-section of stock returns. J. Finance 57, 21132141.

Duffie, D., Garleanu, N., Pederson, L., 2002. Securities lending, shorting, and pricing. J. Financial Econ. 66, 307-339.

Dumas, B., 1989. Two-person dynamic equilibrium in the capital market. Rev. Financial Stud. 2, 157-188.

Dybvig, P.H., Huang, C., 1988. Nonnegative wealth, absence of arbitrage, and feasible consumption plans. Rev. Financial Stud. 1, 377-401.

Gârlenau, N., Panageas, S., 2012.Young, Old, Conservative and Bold: The Implications of Finite Lives and Heterogeneity for Asset Pricing. Working Paper. University of California Berkeley Haas School of Business and University of Chicago Booth School of Business.

Geczy, C., Musto, D.K., Reed, A.V., 2002. Stocks are special too: an analysis of the equity lending market. J. Financial Econ. 66, 241-269.

Grossman, S.J., 1988. An analysis of the implications for stock and futures price volatility of program trading and dynamic hedging strategies. J. Business 61, 275-298.

Grossman, S.J., Zhou, Z., 1996. Equilibrium analysis of portfolio insurance. J. Finance 51, 1379-1403.

Hong, H., Stein, J.C., 2003. Differences of opinion, short-sale constraints, and market crashes. Rev. Financial Stud. 16, 487-525.

Huang, C.F., Litzenberger, R.H., 1988. Foundations for Financial Economics. Elsevier Science Publishers, New York.

Husmann, S., Todorova, N., 2011. CAPM option pricing. Finance Res. Lett. 8, 213-219.

Jones, C.M., Lamont, O.A., 2002. Short-sale constraints and stock returns. J. Financial Econ. 66, 207-239.

Liu, J., Pan, J., 2003. Dynamic derivative strategies. J. Financial Econ. 69, 401-430.

Longstaff, F.A., Wang, J., 2012. Asset pricing and the credit market. Rev. Financial Stud. 25, 3169-3215.

Merton, R., 1990. Capital markets theory and the pricing of financial securities. In: Friedman, B.M., Hahn, F.H. (Eds.), Handbook of Monetary Economics, vol. 1. Cambridge, North-Holland.

Scheinkman, J., Xiong, W., 2003. Overconfidence and speculative bubbles. J. Political Econ. 111, 1183-1219.

Vanden, J.M., 2004. Options trading and the CAPM. Rev. Financial Stud. 17, 207-238.

Wang, J., 1996. The term structure of interest rates in a pure exchange economy with heterogeneous investors. J. Financial Econ. $41,75-110$. 